\title{
Methylphenidate-induced Exacerbation of Chorea in a Child Resolved with Switching to Atomoxetine
}

\author{
Ozalp Ekinci, Cemre Yaşöz, Selin Ayşe İpek Baş, Nazan Ekinci, Özge İpek Doğan \\ Department of Child and Adolescent Psychiatry, Medical Faculty, University of Health Sciences, Istanbul, Turkey
}

\begin{abstract}
Choreiform movements have been reported with stimulant medications, especially in adults. There is only limited evidence on the management of such reactions in children with attention deficit hyperactivity disorder. Hereby, we present the exacerbation of chorea with long-acting methylphenidate use in a 6-year-old child with acute rheumatic fever which resolved with switching to atomoxetine.
\end{abstract}

KEY WORDS: Chorea; Stimulant; Atomoxetine; Attention deficit hyperactivity disorder; Child.

\section{INTRODUCTION}

Stimulant medications, including methylphenidate $(\mathrm{MPH})$, are the first-line treatment for attention deficit hyperactivity disorder (ADHD). Previous reports have shown that stimulants may cause movement-related side-effects including tics, stereotypies, dyskinesia, and chorea [1]. Choreiform movements have been mainly reported in adults and with the use of higher doses of amphetaminergic compounds [2-4]. Since medication treatment is crucial for school-age children with ADHD, strategies should be established for the rare cases where stimulants cause and/or worsen chorea symptoms. Hereby, we present the case of a 6-year-old male with acute rheumatic fever (ARF) who had exacerbation of chorea after starting long-acting MPH which resolved with switching to atomoxetine (ATX).

\section{CASE}

A 6-year old boy was admitted to our clinic with the complaints of attention difficulties, hyperactivity, im-

Received: August 3, 2018 / Revised: November 9, 2018

Accepted: December 13, 2018

Address for correspondence: Ozalp Ekinci

Department of Child and Adolescent Psychiatry, Medical Faculty, University of Health Sciences, Istanbul 34736, Turkey

E-mail: ozalpekinci@yahoo.com

ORCID: https://orcid.org/0000-0001-9598-8944 pulsivity and aggression to peers. His psychiatric evaluation and the parent-rated and teacher-rated scales both indicated an ADHD-combined type diagnosis. Conners' Teacher Rating Scale Score (CTRS) on admission to clinic was 45 [5] while the Turgay DSM-IV Disruptive Behavior Disorders Rating Scale parent form (T-DSM-IV-S) [6] total score was 48 with a hyperactivity subscale score of 24 and an attention deficit subscale score of 24 . His developmental history was reported to be normal. His medical history revealed that he had a streptococcal infection 14 months ago and subsequently had been diagnosed with ARF. As a symptom of ARF, he had Sydenham chorea and stiffness in hand joints but he did not have any cardiac or skin lesions. In his neurologic examination, Sydenham's chorea was evident with mild unintentional movements in the neck and arms. Since the diagnosis of ARF and Sydenham chorea, patient was on haloperidol 1.5 $\mathrm{mg} /$ day, valproate $500 \mathrm{mg} /$ day and 1.200.000 IU benzilpenisilin once in 3 weeks. He had no previous admission to child psychiatry, no history of seizures or any other medical conditions.

For the treatment of ADHD, osmotic-release oral system (OROS) MPH was planned to initiate and the patient was referred to pediatrics department. After the approval of medication by pediatrics department, OROS MPH was started in the dose of $18 \mathrm{mg} /$ day. Three days after MPH treatment, patient was admitted to our clinic with the complaints of worsening of chorea. In his clinical evalua-

(ㄷ) This is an Open-Access article distributed under the terms of the Creative Commons Attribution Non-Commercial License (http://creativecommons.org/licenses/by-nc/4.0) which permits unrestricted non-commercial use, distribution, and reproduction in any medium, provided the original work is properly cited. 
tion, a marked increase in chorea symptoms was observed in arms. In addition, chorea symptoms were observed to emerge in legs, which were not present before MPH treatment. The Chorea Intensity Scale score was 12 on initial admission to clinic and increased to 27 after $\mathrm{MPH}$ treatment. Due to an exacerbation of chorea, $\mathrm{MPH}$ treatment was discontinued. At the 2-week-follow-up, patient's chorea symptoms resolved back to the level before $\mathrm{MPH}$ treatment. At this follow-up, the chorea intensity scale score was found to be 11. After the discontinuation of $\mathrm{MPH}$, no additional medication was initiated for 2 weeks. Thereafter, ATX was started in the dose of 10 $\mathrm{mg} /$ day $(0.5 \mathrm{mg} / \mathrm{kg} /$ day $)$. Ten days follow-up on ATX treatment revealed a mild improvement in ADHD symptoms with no worsening in chorea symptoms. The chorea intensity scale score was 9; while CTRS score was 40 and T-DSM-IV-S total score was 36 , with a hyperactivity subscale score of 19 and an attention deficit subscale score of 17. ATX dose was gradually increased to $18 \mathrm{mg}$ and 25 $\mathrm{mg} /$ day in 3 weeks. Patient was reported to have moderate improvement in ADHD symptoms and no worsening was reported in chorea. The chorea intensity scale score was 9; while CTRS score was 37 and T-DSM-IV-S total score was 28. Figure 1 shows the changes in Chorea Intensity Scale scores during MPH and ATX treatments.

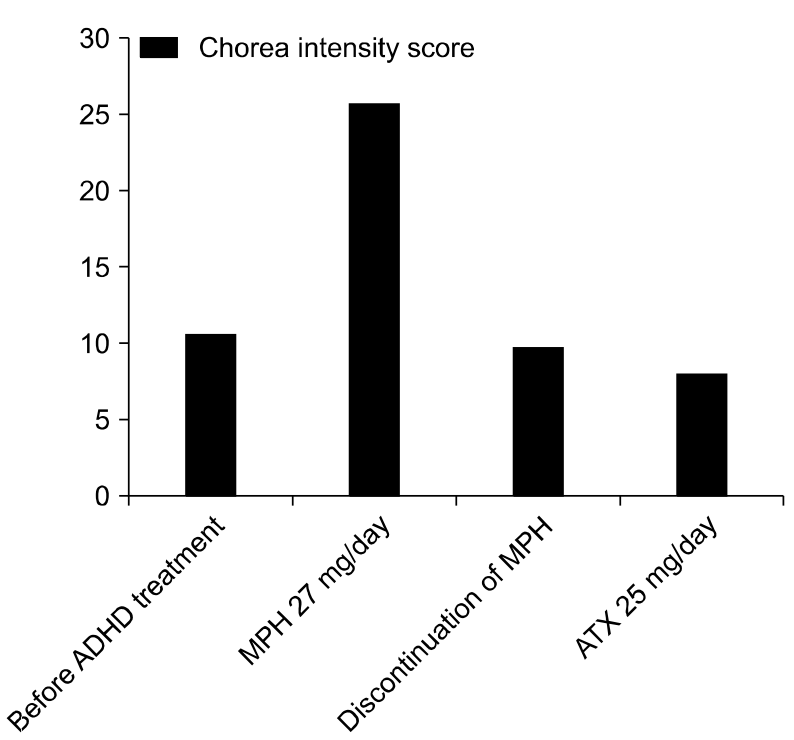

Fig. 1. Changes in Chorea Intensity Scale scores during treatments. ADHD, attention deficit hyperactivity disorder; $\mathrm{MPH}$, methylphenidate; ATX, atomoxetine.

\section{DISCUSSION}

In this case report, the starting of long-acting MPH resulted in a marked exacerbation of chorea in a 6-year-old male with ARF. Thereafter, MPH was discontinued and ATX was initiated. ATX treatment was not found to be linked with worsening of chorea. Moreover, chorea symptoms were slightly decreased with ATX use. To the best of our knowledge, this is the first case which showed an exacerbation of chorea with MPH which resolved with switching to ATX. The mechanism of action of both medications should be taken into account when interpreting the adverse reaction.

There are only few case studies which reported chorea with stimulants in children with ADHD. One of the first reports was by Weiner et al. [7] which presented the case of a young child with ADHD who developed chorea in response to therapeutic dosing of immediate release $\mathrm{MPH}$. Melvin and Heritary [3] reported a 10-year old female who developed chorea, presented by writhing, irregular hand movements and a twisting "dance-like" gait, with the increase of OROS-MPH from $36 \mathrm{mg}$ to $54 \mathrm{mg} /$ day. The adverse effect was reported to discontinue with the stopping of MPH and the addition of lorezepam [3]. Ford et al. [4] also reported a 10-year-old boy who accidently ingested a high dose of lisdexamfetamine dimesylate that resulted in an acute chorea involving arms, legs, and trunk. In this case, haloperidol significantly improved chorea symptoms in approximately 48 hours [4]. The overview of the available literature indicates that both amphetaminergic compounds and MPH may cause choreiform movements. It is known that both formulations inhibit the reuptake of dopamine, while amphetamine increases the release of dopamine from vesicules more selectively [8].

Chorea is defined as a brief, involuntary and hyperkinetic movement disorder [9]. Many potential causes may be linked with chorea including autoimmune processes, infections, hypoxic or ischemic injuries, mitochondrial diseases, and toxins [10]. It has been suggested the excessive dopaminergic activation in corpus striatum, caudate or putamen are largely responsible for choreiform movements $[3,4]$. The primary central nervous system effect of MPH is increased dopaminergic availability, especially in the striatal regions [11]. In the present case, it may be suggested the use of MPH might resulted in an ex- 
acerbation of chorea via increased dopaminergic activity in striatal regions.

It has been described that Sydenham's chorea is commonly associated with psychiatric symptoms, including obsessive-compulsive disorder, tic disorders and ADHD [12]. Antibodies against group A beta-hemolytic streptococcus which cross-react with basal ganglia have been demonstrated as the etiology [13]. The available literature indicates that the treatment of psychiatric disorders is challenging due to the high risk of motor-related side effects of psychotropic medications $[12,14]$. One earlier study found a high frequency of adverse reactions to central stimulants and suggested that Sydenham's chorea in childhood leads to a sensitivity to agents that augment central dopaminergic activity, which may be expressed as acute chorea [15]. The present case may be considered as an example of intolerability to dopaminergic medications.

ATX, a noradrenalin reuptake blocker, is the second-line medication treatment for ADHD [16]. The main actions of ATX were shown to be in the prefrontal cortical regions, while striatal regions are not generally affected. The previous research on ATX use in movement disorders suggests that the medication may be a relatively tolerable alternative in children with tic disorders [17]. In relation with its mechanism of action, there is also evidence that ATX may have benefits on the treatment of tics [18]. It has been shown that a subpopulation of patients with tics may improve under treatment with noradrenergic agents including tricyclic reuptake inhibitors $[19,20]$. Spencer et al. [20] has found ATX treatment associated with significantly greater reduction of tic severity in children with ADHD and Tourette syndrome. Since the neurobiology of tics and chorea are similar, a favorable tolerability and/or a degree of improvement may also be expected in chorea symptoms with ATX treatment. In line with this assumption, ATX use did not cause a worsening of chorea symptoms in the present case and a limited improvement was observed.

The management of stimulant-induced chorea has not been well established. In most of the available literature, stopping the offending agent and, if necessary based on severity of symptoms, administration of dopamine blocking agents or benzodiazepines have been recommended [21]. However, the continuation of ADHD treatment has not been mentioned. ATX, as presented in our case, may be suggested as a candidate treatment option in children where stimulants are discontinued due to worsening of chorea. Future studies are needed to confirm the tolerability and efficacy of ATX in children with ADHD and chorea.

\section{- Conflicts of Interest}

No potential conflict of interest relevant to this article was reported.

\section{Author Contributions}

Conceptualization: Ozalp Ekinci. Acquisition: Ozalp Ekinci, Cemre Yaşöz, Selin Ayşe İpek Baş. Writing-original draft: Ozalp Ekinci, Selin Ayşe İpek Baş, Nazan Ekinci. Review \& editing: Ozalp Ekinci, Özge İpek Doğan.

\section{ORCID}

Ozalp Ekinci https://orcid.org/0000-0001-9598-8944

Cemre Yaşöz https://orcid.org/0000-0002-1192-3519

Selin Ayşe İpek Baş https://orcid.org/0000-0002-0862-6142

Nazan Ekinci https://orcid.org/0000-0002-1503-0654

Özge İpek Doğan https://orcid.org/0000-0003-0572-5521

\section{REFERENCES}

1. Lopez W, Jeste DV. Movement disorders and substance abuse. Psychiatr Serv 1997;48:634-636.

2. Morgan JC, Winter WC, Wooten GF. Amphetamine-induced chorea in attention deficit-hyperactivity disorder. Mov Disord 2004; 19:840-842.

3. Melvin KE, Heiraty P. Acute chorea in a child after starting methy/phenidate: a case report. Cureus 2013;5:e90.

4. Ford JB, Albertson TE, Owen KP, Sutter ME, McKinney WB. Acute, sustained chorea in children after supratherapeutic dosing of amphetamine-derived medications. Pediatr Neurol 2012;47:216-218.

5. Dereboy C, Senol S, Sener S, Dereboy F. [Validation of the Turkish vesions of the short-form Conner's teacher and parent rating scales]. Turk Psikiyatri Derg 2007;18:48-58. Turkish.

6. Ercan ES, Amado S, Somer O, Çıkoğlu S. Development of a test battery for the assessment of attention deficit hyperactivity disorder. Turk J Child Adolesc Ment Health 2001;8:132-144.

7. Weiner WJ, Nausieda PA, Klawans HL. Methylphenidate-induced chorea: case report and pharmacologic implications. Neurology 1978;28:1041-1044.

8. Solanto MV. Neuropsychopharmacological mechanisms of stimulant drug action in attention-deficit hyperactivity disorder: a review and integration. Behav Brain Res 1998;94: 127-152.

9. Cardoso F, Seppi K, Mair KJ, Wenning GK, Poewe W. Seminar on choreas. Lancet Neurol 2006;5:589-602.

10. Wild EJ, Tabrizi SJ. The differential diagnosis of chorea. Pract 
Neurol 2007;7:360-373.

11. Rubia K, Alegria AA, Cubillo Al, Smith AB, Brammer MJ, Radua J. Effects of stimulants on brain function in attention-deficit/hyperactivity disorder: a systematic review and meta-analysis. Biol Psychiatry 2014;76:616-628.

12. Punukollu M, Mushet N, Linney M, Hennessy C, Morton M. Neuropsychiatric manifestations of Sydenham's chorea: a systematic review. Dev Med Child Neurol 2016;58:16-28.

13. Cunningham MW. Rheumatic fever, autoimmunity, and molecular mimicry: the streptococcal connection. Int Rev Immunol 2014;33:314-329.

14. Walker KG, Lawrenson J, Wilmshurst JM. Neuropsychiatric movement disorders following streptococcal infection. Dev Med Child Neurol 2005;47:771-775.

15. Nausieda PA, Bieliauskas LA, Bacon LD, Hagerty M, Koller WC, Glantz RN. Chronic dopaminergic sensitivity after Sydenham's chorea. Neurology 1983;33:750-754.

16. Bushe CJ, Savill NC. Systematic review of atomoxetine data in childhood and adolescent attention-deficit hyperactivity disorder 2009-2011: focus on clinical efficacy and safety. J
Psychopharmacol 2014;28:204-211.

17. Bloch MH, Panza KE, Landeros-Weisenberger A, Leckman JF. Meta-analysis: treatment of attention-deficit/hyperactivity disorder in children with comorbid tic disorders. J Am Acad Child Adolesc Psychiatry 2009;48:884-893.

18. Allen AJ, Kurlan RM, Gilbert DL, Coffey BJ, Linder SL, Lewis DW, et al. Atomoxetine treatment in children and adolescents with ADHD and comorbid tic disorders. Neurology 2005;65: 1941-1949.

19. Spencer T, Biederman J, Coffey B, Geller D, Crawford M, Bearman SK, et al. A double-blind comparison of desipramine and placebo in children and adolescents with chronic tic disorder and comorbid attention-deficit/hyperactivity disorder. Arch Gen Psychiatry 2002;59:649-656.

20. Spencer TJ, Sallee FR, Gilbert DL, Dunn DW, McCracken JT, Coffey $\mathrm{BJ}$, et al. Atomoxetine treatment of $A D H D$ in children with comorbid Tourette syndrome. J Atten Disord 2008;11: 470-481.

21. Gilbert DL. Acute and chronic chorea in childhood. Semin Pediatr Neurol 2009;16:71-76. 